\title{
Democracy, State Capacity, and COVID-19 Related School Closures
}

\author{
Axel Cronert*
}

March 29, 2020

This work is at a very early stage-comments are most welcome

\begin{abstract}
This paper provides a preliminary analysis of the institutional determinants of the timing of COVID-19 related school closures, focusing on the role of democracy and administrative state capacity. To this end, the paper reports a set of survival analyses of school closures around the world in February and March of 2020. Relying foremost on an analysis of the number of days to school closure after the day of the 10th confirmed case of COVID-19 in 134 countries, the paper finds that other things being equal, democratic countries tended to implement school closures more quickly than those with a more authoritarian regime, while countries with higher government effectiveness tended to take longer than those with less effective state apparatuses. Similar, yet - with respect to democracy - less substantial results are retrieved in a supplementary analysis of 158 countries, where the starting point is instead the day of China's first COVID-19 related school closure. Note that these results are preliminary and that the paper is not intended to evaluate, and does not say anything about, the appropriateness or effectiveness of any particular school closure strategy.
\end{abstract}

Keywords: coronavirus disease 2019 (COVID-19), democracy, administrative state capacity, school closure, survival analysis, event history analysis

*Department of Government, Uppsala University. Email: axel.cronert@statsvet.uu.se. 


\section{Introduction}

The recent weeks have seen governments across the world respond rapidly and with and unprecedentedly disruptive measures to address the spread of coronavirus disease 2019 (COVID-19), including school closures, travel restrictions, curfews and quarantines.

As questions about how to understand and handle the pandemic and its aftermath now surge on the research agendas across disciplines, a key task for political scientists will be to analyze why states responded the way they did. Although it is still too early for any comprehensive analysis of the crisis response, it is possible to analyze - at least preliminarily - one measure that has already been remarkably widely implemented and for which comprehensive and comparable data is already available, namely school closures. As the data from UNESCO (2020) reported in Figure 1 shows, the four weeks that followed after the first COVID-19 related school closure occurred in China on February 16 saw a striking 120 countries implement a localized or national school closure, and after an additional ten days, on March 25, a total of 172 countries had followed suit.

The widespread implementation of school closures may not come as a surprise, given that they may help slow the spread of the virus by increasing social distancing and the likelihood that exposed individuals develop symptoms while not in school

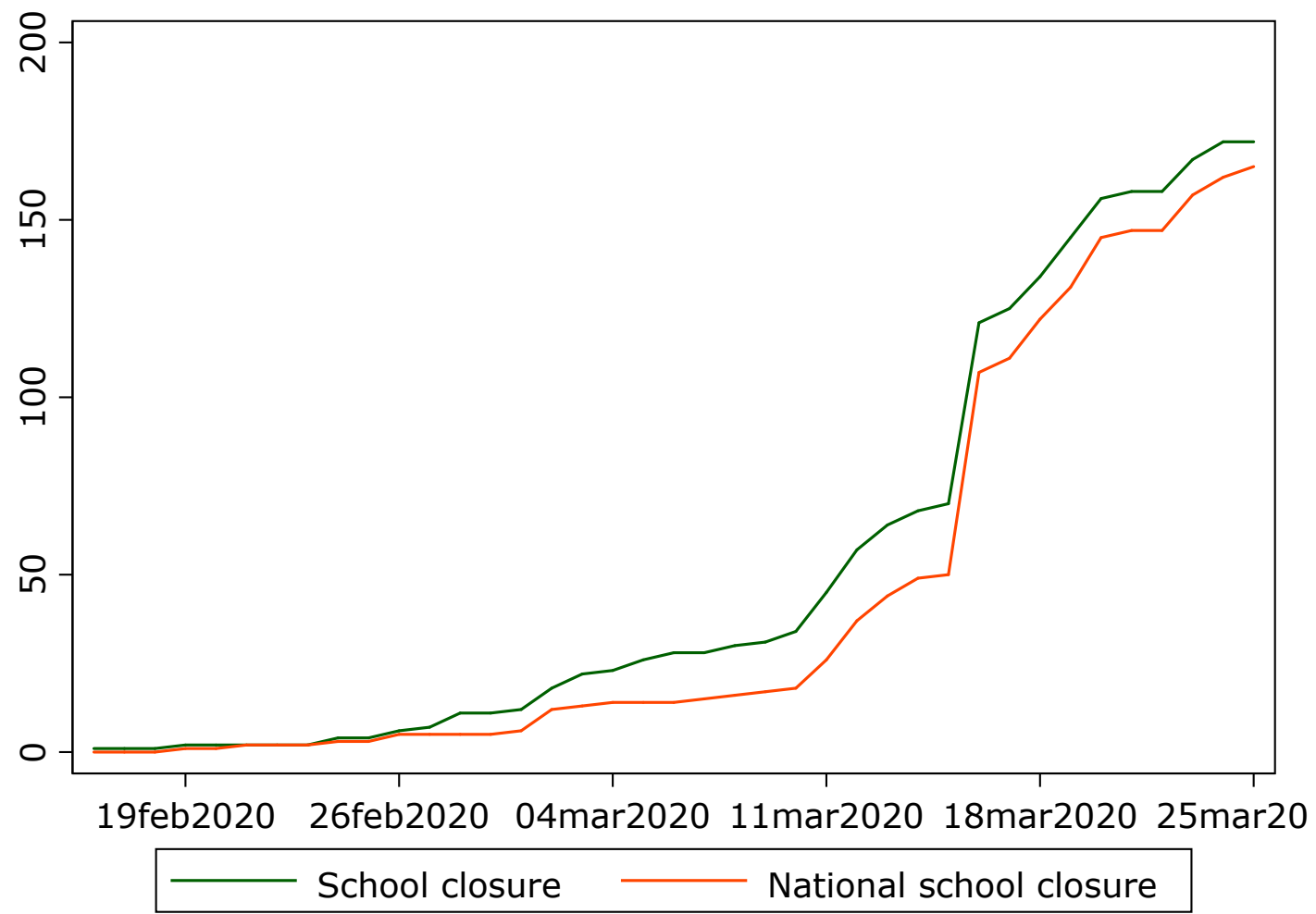

Figure 1: National and localized school closures caused by COVID-19 since February 16, 2020. Source: UNESCO (2020). 
(CSSE 2020; Jackson et al. 2013; WHO 2019). However, depending on when and for long they are implemented, school closures may also put older relatives at higher risk, have detrimental effects on student performance and well-being, and decrease the workforce in health care and other important capacities as more parents stay home with children (CSSE 2020). Thus, given that the timing of school closures appears be of critical importance for their outcomes, it is of interest to know whether certain political and institutional factors systematically matter for the timing of a country's decision to implement a school closure.

\section{Democracy, State Capacity, and the Timing of School Closures: Initial Theoretical Remarks}

In this paper, I focus on two such factors of longstanding interest to social scientistsdemocracy and administrative state capacity. Pending the development of a more sophisticated theoretial framework for COVID-19 responses, it is not apriori clear what role to expect from either of these factors in determining the timing of school closures.

Consider first democracy, which is commonly conceived as the extent to which rulers and the policy choices they make are responsive to citizens, achieved through freedom of expression and association, clean elections, elected officials, and extensive suffrage (Dahl 1971). On the one hand, one might expect that democratically elected leaders may find it more important to promptly signal decisiveness in times of national crisis to boost public approval, especially in cases where an election is imminent. In addition, freedom of expression may improve the quality of information available to governments, which may enable a quicker crisis response (Kahn 2005; Persson and Povitkina 2017). Furthermore, to the extent that a quicker reply indeed reflects a greater commitment to public health, we should expect democracies to act faster as they tend to put higher priority on the population's well-being (Besley and Kudamatsu 2006; Cronert and Hadenius forthcoming). On the other hand, it is also possible that a measure as drastic as a school closure is more difficult to enact in a democratic country where a larger share of the population - many of whom will be personally and immediately affected by the measure - are able to have a say in politics, whether individually or through civil associations. For a formal argument along these lines, applied to the case of mass vaccination, see Ahlskog (2017, Essay I).

It is also not obvious what to expect regarding administrative state capacity, by which we typically refer to the extent to which competent, efficient and impartial administrative agencies enable the state to take action in an appropriate and effective manner (Bäck and Hadenius 2008). On the one hand, drawing on earlier research about the importance of government effectiveness for a successful response to natural disasters, one might expect that high state capacity enable countries to prepare for and implement school closures more rapidly (Kahn 2005; Persson and Povitkina 2017; Raschky 2008). On the other hand, it is possible that countries with more well-functioning state agencies also find themselves with a larger set 
of policy tools available for consideration, and thus are in a better position to suspend drastic measures like school closures longer in favor of a less disruptive initial response. The cases of Sweden and Singapore are consistent with the latter expectation. The countries differ in their level of democracy but score very high in terms of government effectiveness and did not implement their (partial) school closures until March 18 and April 1 (announced on March 27), respectively. In Sweden, when other European democracies began closing schools in early March, the politically independent Public Health Agency defended the country's deviating strategy with reference to the large disruption and to the importance of timing, while government representatives customarily declared adherence to the agency's recommendation (Rothschild 2020). A similar reasoning was provided by the Singaporean minister of education when annonuncing its school closure on March 27: "for schools, which are a major part of people's lives, we have also been stepping up (measures). So we will not want to do something dramatic, sudden, that will result in school closure [...] We still have options. We are not like many countries, where they are forced into sudden school closures" (Teng and Davie 2020).

\section{Empirical analysis}

In the following, I investigate the role of democracy and administrative state capacity in determining the timing of COVID-19 related school closures around the world, in an event history (survival analysis) framework. This is done first by means of simple graphical illustration, and second by means of regression analysis.

To enable a meaningful comparison of timing, we need to define a common starting point for the analysis. To enable two complementary analyses with different scopes in terms of countries and variables, I have chosen two different starting points. For the main analysis, the comparison starts at the first day in which at least 10 cases had been confirmed according to the CSSE data - the rationale being that after 10 confirmed cases, we can arguably be safe to assume that a government has at least begun to consider various crises responses. ${ }^{1}$ This criterion includes 134 countries, among which 122 had implemented a school closure by the time the analysis ends on March 25. The models include 108 or 113 of these countries, depending on specification. However, this criterion leaves out a considerable group of countries that do not yet have 10 confirmed cases, yet had nonetheless already implemented school closures. Therefore, to include as many countries as possible in the study, I also conduct a supplementary set of analyses with fewer controls variables, beginning for all countries on February 16, the day that China implemented the first COVID-19 related school closure. Due to incomplete data, this set of analyses includes at most 158 countries, 144 of which had implemented a school closure by March 25 .

\footnotetext{
${ }^{1}$ Lowering the cut-off to five cases produces similar results.
} 


\subsection{Data}

To measure a country's level of democracy in 2019, I primarily rely on the electoral democracy index provided by the V-Dem Institute (Coppedge 2020), and as an indicator of administrative state capacity I use the Worldwide Governance Indicators' (WGI) 2018 estimate of government effectiveness (Kaufmann et al. 2011). In a robustness check with slightly fewer countries, I use the 2019 Freedom House/Imputed Polity level of democracy indicator (Freedom House 2019) and the 2016 ICRG indicator of quality of government (PRS Group 2019). All four indicators are transformed so as to range between 0 and 10. Data on daily incidents of school closures are retrieved from UNESCO (2020), daily data on domestical and regional confirmed cases of COVID-19 come from the CSSE (2020) at Johns Hopkins University, and a number of control variables are retrieved from Teorell (2020). See Appendix I for detailed definititions and sources.

\subsection{Graphical results}

Let us begin by considering some graphical results. First, Figure 2 reports a plot of Kaplan-Meier failure rates, where failure represents the first national or localized school closure. For illustrative purposes, the graph divides the 134 countries that have 10 or more confirmed cases into four groups, based on whether they belong to the top half or bottom half of countries in the sample with respect to democracy (V-Dem) and state capacity (WGI), respectively.

The figure shows that the group of 12 countries with an above-median level of democracy and a below-median level of state capacity was the first to reach a 100 percent school closure rate - no more than 8 days after the tenth observed case - soon to be followed by the larger group of countries with below-median levels in both indicators. By contrast, the group of 13 countries with low levels of democracy and high state capacity is the group that took longest, despite some of them, like Saudi Arabia and Hungary closing schools within one day. After more than 40 days, still no more than 8 (62 percent) had implemented a school closure, and both Singapore and Oman had still not closed by March 25. Contrastingly, the large group of countries with above-median scores in both indicators had gradually reached an 80 (90) percent school closure rate within 18 (33) days from the 10th confirmed case.

Next, for each country that had implemented a school closure by March 25, Figure 3 plots the number of days between the country's closure and the day of the 10th confirmed case against the country's government effectiveness rating. The

color of the markers indicate whether the country has a below-median (orange) or above-median (green) democracy rating. It is clear from the figure that most of the countries that took longer than two weeks are countries with very high state capacity, almost all of which are also democracies. Interestingly, among the countries with a medium level of state capacity, the few countries that clearly deviate upwards in days to closure have a below-median level of democracy. 


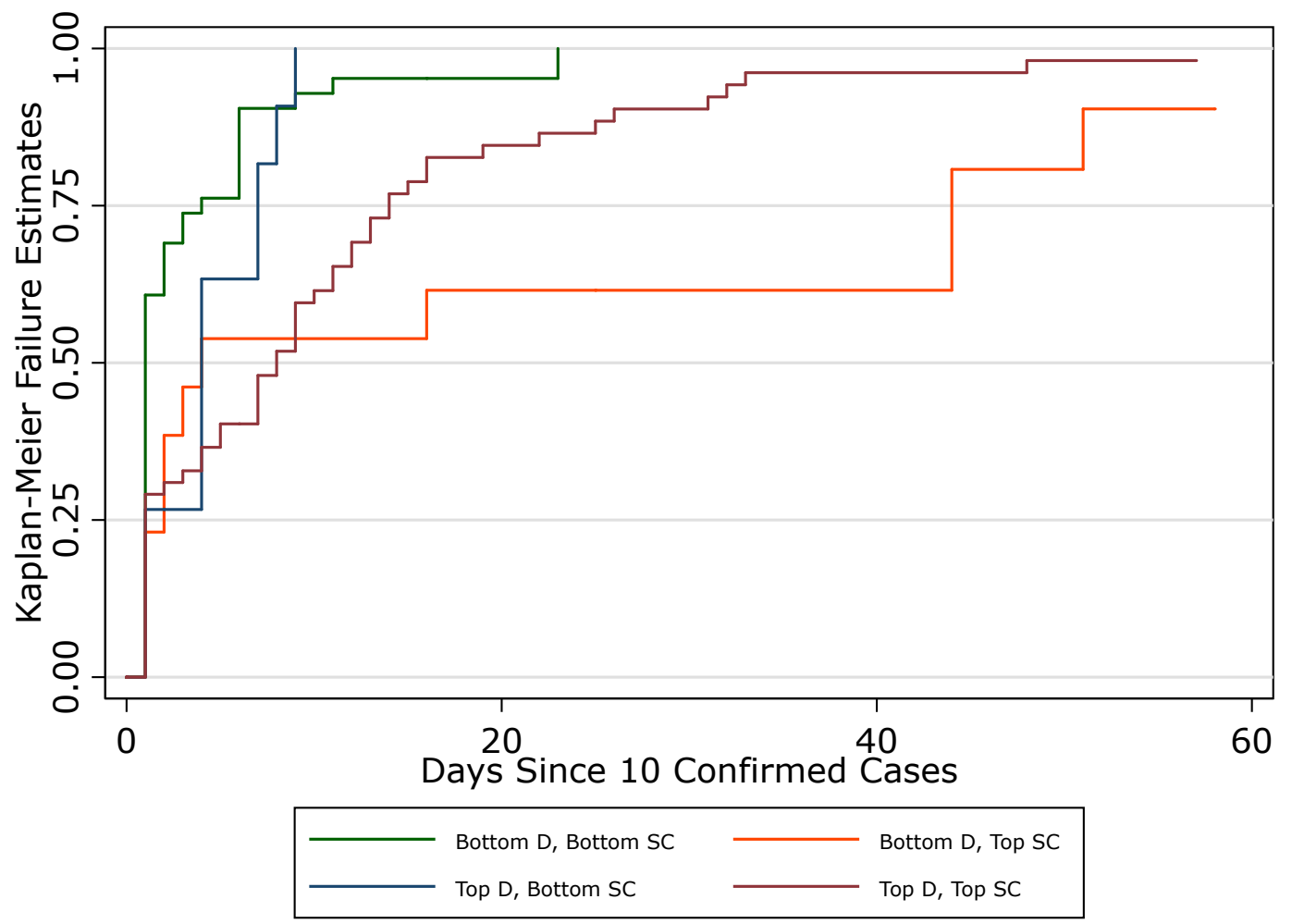

Figure 2: Kaplan Meier failure rates for 134 countries with 10 or more confirmed cases, categoried according to whether they belong to the top half or bottom half of countries in the sample with respect to democracy (D) and state capacity (SC).

\subsection{Regression analysis}

The tentative cue from the simple graphical results above is that democracies appears to implement school closures more quickly than more authoritarian countries as a response to the spread of COVID-19, while countries with more effective state apparatuses tend to take longer than those with more limited state capacity. As it turns out, similar results are retrieved from the regression analyses summarized in Figure 4 and reported in full in Appendix II.

Figure 4 reports two sets of three survival analysis models. Set A uses the V-Dem's democracy index and the WGI government effectiveness indicator as the key independent variables, while set B uses the Freedom House/Imputed Polity democracy indicator and the ICRG indicator of quality of government. The first two models in each set consider the 134 countries with 10 or more confirmed cases. The first specification is a parametric model with an exponential survival distribution and the second is a non-parametric Cox model. Both models include a shared frailty at the country level and a number of control variables.

First, I include the (logged) number of confirmed domestic cases and the average (logged) number of confirmed cases among the other countries in the same region, as well as a set of region dummies as defined by the World Bank. Second, I add a number of factors that are likely to be correlated with democracy and state 


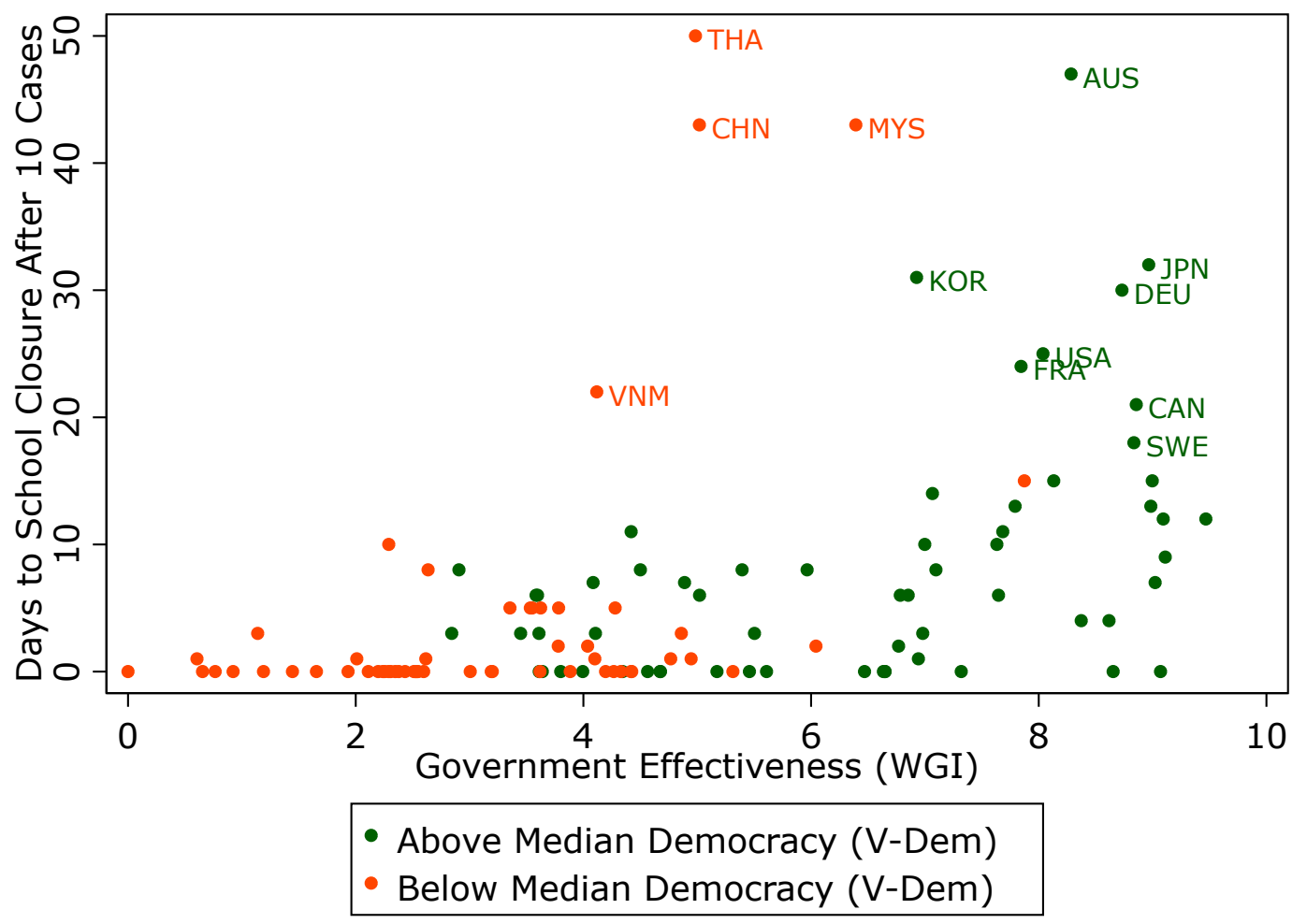

Figure 3: Y-axis: Days to school closure after 10 confirmed cases. X-axis: Government effectiveness (Kaufmann et al. 2011). Orange markers indicate below-median democracy (V-Dem) and green markers denote above-median democracy. Includes 134 countries.

capacity, and which may also affect the time to school closure: a measure of the population health (healthy life expectancy), the gross preprimary school enrollment rate $^{2}$, the share of the population aged 65 or above, and population density. Lastly, I include a dummy indicating country-specific weekend days, considering that a school closure should be much more likely to begin on a working day.

All four models indicate that other things being equal, democratic countries are likely to implement school closures sooner than those with a more authoritarian regime. The exponentiated coefficients indicate that an increase in democracy by one unit (on a $0-10$ scale) is associated with an increase in the relative risk of school closure of around 24 percent for the V-Dem indicator and around 16 percent for the Freedom House/Imputed Polity indicator. As to state capacity, a one unit increase in the WGI or the ICRG indicator is associated with a 22-28 percent lower relative risk of school closure. All results are statistically significant at conventional levels.

As to the other indicators in these models, we expectedly find that a larger number of confirmed cases - domestically and regionally - is associated with a

\footnotetext{
${ }^{2}$ The primary school enrollment rate shows much less variation among countries and also does not appear to be related to school closure timing.
} 


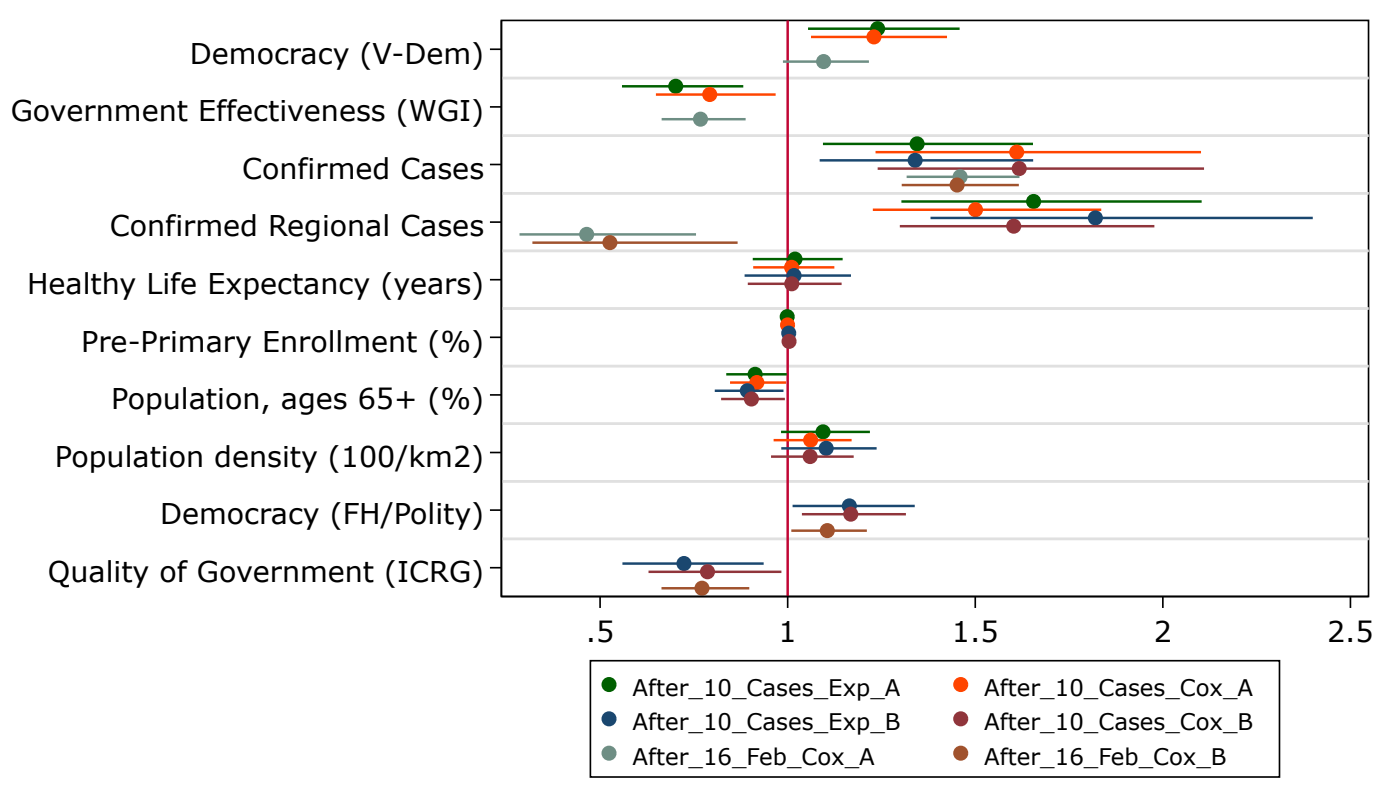

Figure 4: Exponentiated regression coefficients from survival models with shared country frailties. Set A and B use different indicators for democracy and state capacity. 'Exp' denotes parametric models with an exponential survival distribution, 'Cox' denotes non-parametric Cox models. All models also include world region dummies and an indicator for weekend days.

more rapid school closure. The results furthermore indicate that countries with an older population tended to implement school closures less quickly, while a higher population density appears to be related to a quicker response - although the coefficient for the latter does not reach statistical significance.

In the interest of extending the analysis to as many countries as possible, the last two models reported in the figure consider all observed countries (except China) beginning on February 16, the day of China's school closure. A drawback of this model is that to maximize the number of included countries, the selection of control variables needs to be limited to confirmed cases, region dummies, and the weekend indicator. In this analysis, only a Cox model is reported since that is the only one with a shared country-level frailty that can be fitted to the data using Stata. In this larger sample, the effects of both democracy and state capacity is considerably reduced, and in the case of the V-Dem democracy indicator, the p-value drops slightly below statistical significance $(p=0.085)$. While this does raise some concerns regarding the interpretaton of the role of democracy thus far, it should be kept in mind that since this model includes fewer variables and the starting date is not as clearly related to the spread of the virus, the results from this model should be interpreted with some more caution. 

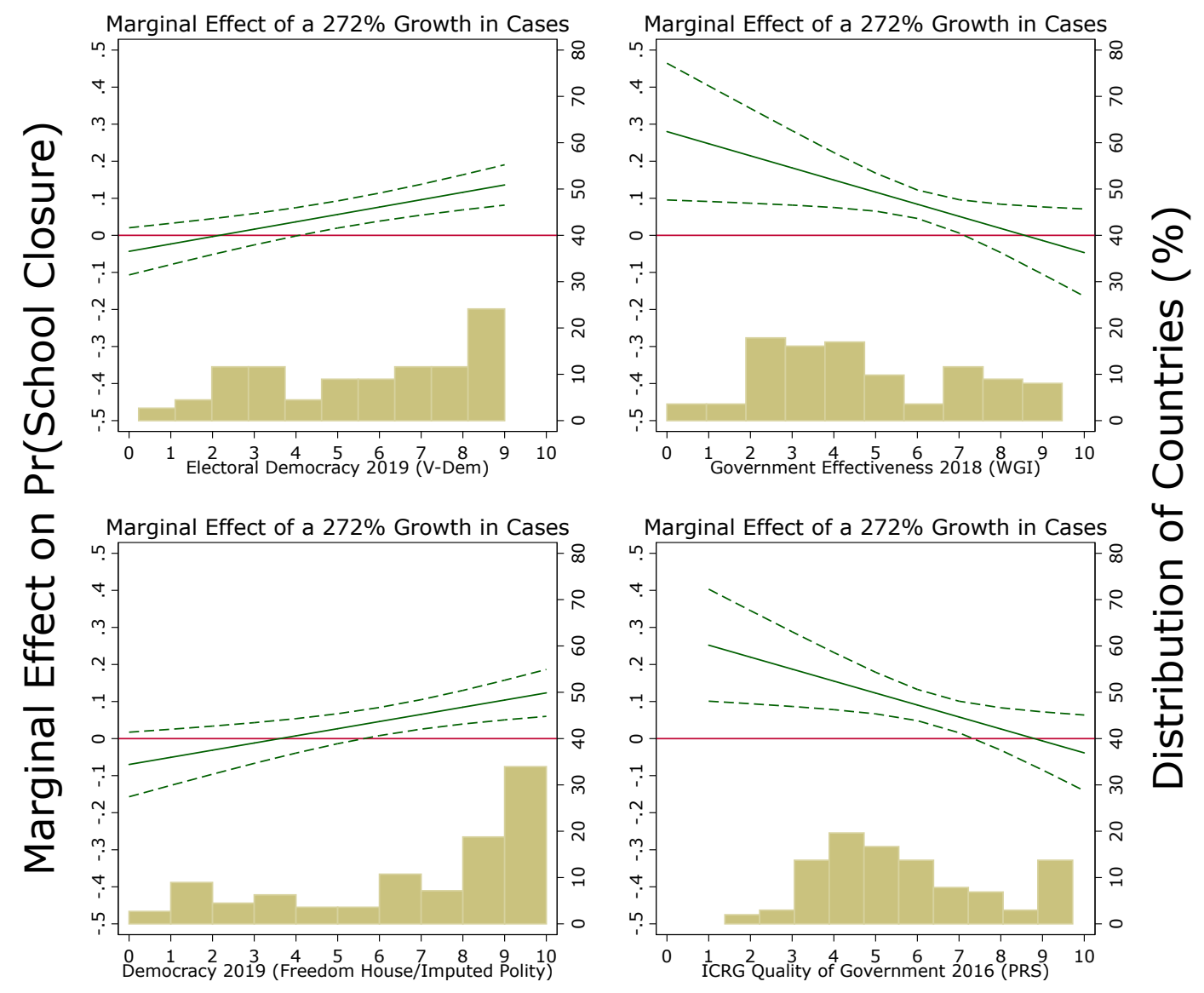

Figure 5: The conditional effect of a 272 percent growth in the number of confirmed cases on school closure, conditional on democracy and state capacity respectively, and with all other variables held at their means. Estimates are based on the linear probability models with country fixed effects reported in Table 2.

\subsection{Linear probability fixed effects models}

Lastly, in an attempt to shed light on the mechanisms in play here, two final models investigate how the estimated effect of an increase in confirmed domestic cases of COVID-19 on the relative risk of school closure varies across countries with different characteristics. To enable the necessary estimation of multiple interaction effects to explore this issue, these models are specified as linear probability model of school closure with country fixed effects, where time dependence is modelled with cubic splines. I include six interaction terms between (logged) confirmed domestic cases and democracy, state capacity, and the four control variables (omitting the set of region dummies, which come out insignificant in both models). These models, reported in full in Appendx II, indicate that an increase in the number of confirmed cases is associated with a higher increase in the probability of school closure at lower levels of state capacity, whereas the opposite pattern emerges for democracy.

These conditional relationships are presented graphically in Figure 5, which 
reports how the estimated effect of a 272 percent growth in the number of confirmed cases on the predicted probability of school closure varies between countries that differ in terms of democracy and state capacity but have average values on the other factors. With respect to democracy, the models suggest that for highly democratic countries such an increase is associated with an approximately 10 percentage points higher probability of school closure, whereas for more authoritarian states the corresponding association is around or slightly below 0. As to state capacity, the association is around zero and insignificant for states scoring high, while for a typical country around the middle of the estimated increase in probability of school closure is at around 10 percentage points or higher. These results lend some additional support to the notion that countries with different levels of democracy and administrative state capacity responded differently to the spread of COVID-19.

\section{Concluding remarks}

This paper has provided an initial investigation of how two institutional factorsdemocracy and administrative state capacity — help determine the varying timing of countries' implementation of school closures as a response to the spread of COVID-19 in the spring of 2020.

Overall, the preliminary evidence presented in this paper indicates that a higher level of democracy in a country was associated with a more rapid implementation of a school closure, whereas a higher level of state capacity was associated with a more delayed implementation. However, a few caveats are warranted. First, although aimed at including as many countries as possible, the analyses reported here do not cover the universe of countries. Given that some countries have not implemented a school closure at the time of writing, but may eventually do so, it is too early to draw any definitive conclusions from these results. Second, the quality of the information on the number of confirmed cases of COVID-19 is likely to vary between countries, which might affect the results in various ways, given the importance of this variable in the models. Third, I want to emphasize that the analyses reported here are not intended to evaluate, nor do they say anything about, the appropriateness or effectiveness of any particular school closure strategy.

Lastly, it should be highlighted that school closure is only one among many types of government responses to COVID-19, and it is not clear how the patterns observed here travel to other types of more or less disruptive measures. As more data become available - for instance through the Oxford COVID-19 Government Response Tracker (Hale and Webster 2020) - comparing different types of responses will be a crucial research endeavor, along with efforts to develop more detailed theories and hypotheses about which aspect of democracy and state capacity it is that actually matters. For instance, given the results reported here, one important follow-up question concerns whether the more important reason why democracies apparently responded faster is electoral considerations, more accurate information, or a stronger commitment to public health. Furthermore, while the present study has relied on a rather specific conceptualization of state capacity as administrative effectiveness, future work should also consider the possible role of 
the state's extractive (fiscal) and coercive capacities in responding to the COVID-19 pandemic.

\section{References}

Ahlskog, Rafael (2017). Essays on the collective action dilemma of vaccination. Digital Comprehensive Summaries of Uppsala Dissertations from the Faculty of Social Sciences, ISSN 1652-9030; 134.

Bäck, Hanna and Axel Hadenius (2008). 'Democracy and state capacity: exploring a J-shaped relationship'. Governance 21.1, 1-24.

Besley, Timothy and Masayuki Kudamatsu (2006). 'Health and democracy'. American economic review 96.2, 313-318.

Coppedge Michael, et al. (2020). V-Dem Dataset v10. https://doi.org/10.23696/vdemds20.

Cronert, Axel and Axel Hadenius (forthcoming). 'Institutional Foundations of Global Wellbeing: Democracy, State Capacity, and Social Protection'. International Political Science Review.

CSSE (2020). Confirmed cases of COVID-19. 2019 Novel Coronavirus COVID-19 (2019-nCoV) Data Repository. CSSE at Johns Hopkins University. https://raw.githubusercontent.com/CSSEGISandData/.

Dahl, Robert Alan (1971). Polyarchy: Participation and Opposition. Yale University Press.

Freedom House (2019). Freedom in the world 2019.

Hale, Thomas and Samuel Webster (2020). Oxford COVID-19 Government Response Tracker. https://www.bsg.ox.ac.uk/research/research-projects/oxfordcovid-19-government-response-tracker.

Jackson, Charlotte, Emilia Vynnycky, Jeremy Hawker, Babatunde Olowokure, and Punam Mangtani (2013). 'School closures and influenza: systematic review of epidemiological studies'. BMJ open 3.2, e002149.

Kahn, Matthew E (2005). 'The death toll from natural disasters: the role of income, geography, and institutions'. Review of economics and statistics 87.2, 271-284.

Kaufmann, Daniel, Aart Kraay, and Massimo Mastruzzi (2011). 'The worldwide governance indicators: methodology and analytical issues'. Hague Journal on the Rule of Law 3.2, 220-246.

Persson, Tove Ahlbom and Marina Povitkina (2017). "Gimme shelter": The role of democracy and institutional quality in disaster preparedness'. Political Research Quarterly 70.4, 833-847.

PRS Group, et al. (2019). International country risk guide.

Raschky, Paul A (2008). 'Institutions and the losses from natural disasters'. Natural hazards and earth system sciences 8.4, 627-634.

Rothschild, Nathalie (2020). Sweden Is Open for Business During Its Coronavirus Outbreak. Foreign Policy, March 24, 2020.

Teng, Amelia and Sandra Davie (2020). Coronavirus: Students to do home-based learning once a week from April as schools step up safe-distancing measures. Straits Times, March 27, 2020. 
Teorell Jan, et al. (2020). The Quality of Government Standard Dataset, version Jan20.

UNESCO (2020). Data from Unesco's Global Monitoring of School Closures Caused by COVID-19. https://en.unesco.org/themes/education-emergencies/coronavirusschool-closures.

WHO (2019). Non-pharmaceutical public health measures for mitigating the risk and impact of epidemic and pandemic influenza: annex: report of systematic literature reviews. Tech. rep. World Health Organization.

Wikipedia (2020). Workweek and weekend. Retrieved on March 29, 2020 . https://en.wikipedia.org/wiki/Workweek_and_weekend. 


\section{Appendix I: Variables and Data}

- School closures (daily): Data (until March 25, 2020) from UNESCO (2020) Includes both localized and national measures.

- Confirmed cases of COVID-19 (daily): Data (until March 25, 2020) from the CSSE (2020) at Johns Hopkins University. Computed as $\ln (1+$ cases $)$.

- Democracy (V-Dem) (2019): The Varieties of Democracy Institute's electoral democracy index, which measures to what extent the ideal of electoral democracy in its fullest sense is achieved, and measures when suffrage is extensive; political and civil society organizations can operate freely; elections are clean and not marred by fraud or systematic irregularities; and elections affect the composition of the chief executive of the country. Rescaled to 0-10. Source: Coppedge (2020).

- Government effectiveness (WGI) (2018): A composite measure that considers the quality of public service provision, the quality of the bureaucracy, the competence of civil servants, the independence of the civil service from political pressures, and the credibility of the government's commitment to policies. Rescaled to 0-10. Source: Worldwide Governance Indicators (Kaufmann et al. 2011), retrieved from Teorell (2020).

- Democracy (Freedom House/Imputed Polity) (2019): Scale ranges from 0-10 where 0 is least democratic and 10 most democratic. Average of Freedom House is transformed to a scale $0-10$ and Polity is transformed to a scale $0-10$. These variables are averaged into fh_polity2. The imputed version has imputed values for countries where data on Polity is missing by regressing Polity on the average Freedom House measure. Source: Freedom House (2019), retrieved from Teorell (2020).

- Quality of government (ICRG) (2016): The mean value of the ICRG variables Corruption, Law and Order and Bureaucracy Quality, scaled 0-10. Higher values indicate higher quality of government. Source: PRS Group (2019) retrieved from Teorell (2020).

- Healthy life expectancy (2016): Healthy life expectancy (HALE) at birth (years). Source: World Health Organization, retrieved from Teorell (2020).

- Population, ages 65+ (2016): Population ages 65 and above as a percentage of the total population. Population is based on the de facto definition of population, which counts all residents regardless of legal status or citizenship. Source: The World Bank's World Development Indicators, retrieved from Teorell (2020).

- Population density (2016): Midyear population divided by land area in square kilometers, multiplied by 100. Source: The World Bank's World Development Indicators, retrieved from Teorell (2020). 
- Preprimary school enrollment (WDI) (2018): Total enrollment in preprimary education, regardless of age, expressed as a percentage of the total population of official pre-primary education age. Source: The World Bank's World Development Indicators, retrieved from Teorell (2020).

- Weekend: A dummy for days that are not working days, as listed on Wikipedia (2020). Saturday-Sunday is assumed if information is missing.

\section{Appendix II: Regression Tables}


Table 1: Event history analysis of time to school closure.

\begin{tabular}{|c|c|c|c|c|c|c|}
\hline & (1) & $(2)$ & (3) & (4) & $(5)$ & (6) \\
\hline \multirow[t]{2}{*}{ Democracy (V-Dem) } & $1.240^{* * *}$ & $1.230^{* * *}$ & & & $1.096^{*}$ & \\
\hline & $(0.103)$ & $(0.092)$ & & & $(0.058)$ & \\
\hline \multirow[t]{2}{*}{ Government Effectiveness (WGI) } & $0.702^{* * *}$ & $0.792^{* *}$ & & & $0.768^{* * *}$ & \\
\hline & $(0.082)$ & $(0.081)$ & & & $(0.057)$ & \\
\hline \multirow[t]{2}{*}{ Confirmed Cases } & $1.345^{* * *}$ & $1.611^{* * *}$ & $1.340^{* * *}$ & $1.617^{* * *}$ & $1.460^{* * *}$ & $1.452^{* * *}$ \\
\hline & $(0.142)$ & $(0.219)$ & $(0.144)$ & $(0.219)$ & $(0.077)$ & $(0.079)$ \\
\hline \multirow[t]{2}{*}{ Confirmed Regional Cases } & $1.656^{* * *}$ & $1.501^{* * *}$ & $1.820^{* * *}$ & $1.603^{* * *}$ & $0.464^{* * *}$ & $0.526^{* *}$ \\
\hline & $(0.202)$ & $(0.154)$ & $(0.257)$ & $(0.172)$ & $(0.115)$ & $(0.134)$ \\
\hline \multirow[t]{2}{*}{ East Asia \& Pacific } & 1.000 & 1.000 & 1.000 & 1.000 & 1.000 & 1.000 \\
\hline & $()$. & $()$. & $()$. & $()$. & $()$. & $()$. \\
\hline \multirow[t]{2}{*}{ Europe \& Central Asia } & $4.483^{* * *}$ & $4.000^{* *}$ & $6.018^{* * *}$ & $4.582^{* *}$ & $2.803^{* * *}$ & $3.392^{* * *}$ \\
\hline & $(2.443)$ & $(2.350)$ & $(3.503)$ & $(2.874)$ & $(0.914)$ & $(1.251)$ \\
\hline \multirow[t]{2}{*}{ Latin America \& Caribbean } & $3.365^{* *}$ & $3.390^{* *}$ & $5.335^{* * *}$ & $3.762^{* *}$ & $0.221^{* *}$ & 0.379 \\
\hline & $(1.986)$ & $(1.950)$ & $(3.322)$ & $(2.230)$ & $(0.147)$ & $(0.261)$ \\
\hline \multirow[t]{2}{*}{ Middle East \& North Africa } & $2.663^{*}$ & $3.187^{* *}$ & $4.103^{* *}$ & $4.188^{* *}$ & $2.527^{* *}$ & $5.025^{* * *}$ \\
\hline & $(1.530)$ & $(1.804)$ & $(2.510)$ & $(2.481)$ & $(0.976)$ & $(2.141)$ \\
\hline \multirow[t]{2}{*}{ North America } & 3.085 & 3.869 & 4.788 & 5.229 & $35.721^{* * *}$ & $30.648^{* * *}$ \\
\hline & $(3.922)$ & $(4.602)$ & $(6.355)$ & $(6.376)$ & $(39.716)$ & $(35.082)$ \\
\hline \multirow[t]{2}{*}{ South Asia } & $9.920^{* * *}$ & $7.359^{* *}$ & $17.582^{* * *}$ & * $9.023^{* * *}$ & 1.694 & $3.205^{*}$ \\
\hline & $(8.650)$ & $(5.928)$ & $(16.966)$ & $(7.664)$ & $(0.961)$ & $(2.214)$ \\
\hline \multirow[t]{2}{*}{ Sub-Saharan Africa } & $7.609^{* *}$ & $5.435^{* *}$ & $14.961^{* * *}$ & * $7.783^{* *}$ & $0.101^{* *}$ & 0.253 \\
\hline & $(6.263)$ & $(4.147)$ & $(14.021)$ & $(6.520)$ & $(0.092)$ & $(0.234)$ \\
\hline \multirow[t]{2}{*}{ Healthy Life Expectancy (years) } & 1.020 & 1.011 & 1.017 & 1.011 & & \\
\hline & $(0.061)$ & $(0.055)$ & $(0.072)$ & $(0.064)$ & & \\
\hline \multirow[t]{2}{*}{ Pre-Primary Enrollment (\%) } & 0.999 & 1.000 & 1.003 & 1.004 & & \\
\hline & $(0.007)$ & $(0.006)$ & $(0.007)$ & $(0.006)$ & & \\
\hline \multirow[t]{2}{*}{ Population, ages $65+(\%)$} & $0.913^{* *}$ & $0.918^{* *}$ & $0.893^{* *}$ & $0.904^{* *}$ & & \\
\hline & $(0.041)$ & $(0.038)$ & $(0.047)$ & $(0.043)$ & & \\
\hline \multirow[t]{2}{*}{ Population density $(100 / \mathrm{km} 2)$} & 1.094 & 1.061 & $1.103^{*}$ & 1.060 & & \\
\hline & $(0.060)$ & $(0.053)$ & $(0.065)$ & $(0.056)$ & & \\
\hline \multirow[t]{2}{*}{ Weekend } & $0.313^{* * *}$ & $0.328^{* * *}$ & $0.351^{* * *}$ & $0.358^{* * *}$ & 0.382 & $0.250^{* *}$ \\
\hline & $(0.097)$ & $(0.097)$ & $(0.109)$ & $(0.109)$ & $(0.236)$ & $(0.170)$ \\
\hline \multirow[t]{2}{*}{ Democracy (FH/Polity) } & & & $1.165^{* *}$ & $1.168^{* * *}$ & & $1.106^{* *}$ \\
\hline & & & $(0.083)$ & $(0.071)$ & & $(0.051)$ \\
\hline \multirow[t]{2}{*}{ Quality of Government (ICRG) } & & & $0.724^{* *}$ & $0.786^{* *}$ & & $0.772^{* * *}$ \\
\hline & & & $(0.095)$ & $(0.090)$ & & $(0.059)$ \\
\hline Observations & 812 & 812 & 801 & 801 & 4329 & 3576 \\
\hline Countries & 113 & 113 & 108 & 108 & 158 & 158 \\
\hline$A I C$ & 281.704 & 755.005 & 260.741 & 684.450 & 1200.665 & 985.047 \\
\hline$B I C$ & 361.595 & 825.497 & 340.400 & 754.738 & 1270.769 & 1053.049 \\
\hline
\end{tabular}

Standard errors in parentheses. ${ }^{*} p<0.10,{ }^{* *} p<0.05,{ }^{* * *} p<0.01$. 
Table 2: Linear probability models of school closure after 10 confirmed cases.

\begin{tabular}{lcc}
\hline \hline & $(1)$ & $(2)$ \\
\hline Confirmed Cases & $0.984^{* *}$ & $0.796^{*}$ \\
& $(0.396)$ & $(0.419)$ \\
Confirmed Regional Cases & $0.113^{* *}$ & $0.129^{* * *}$ \\
& $(0.054)$ & $(0.049)$ \\
Weekend & -0.041 & -0.039 \\
& $(0.108)$ & $(0.107)$ \\
Confirmed Cases $\times$ Democracy (V-Dem) & $0.020^{* * *}$ \\
& $(0.005)$ \\
Confirmed Cases $\times$ Government Effectiveness (WGI) & $-0.033^{* *}$ \\
& $(0.015)$ \\
Confirmed Cases $\times$ Healthy Life Expectancy (years) & $-0.013^{*}$ & -0.010 \\
& $(0.007)$ & $(0.007)$ \\
Confirmed Cases $\times$ Pre-Primary Enrollment (\%) & 0.000 & 0.000 \\
& $(0.001)$ & $(0.001)$ \\
Confirmed Cases $\times$ Population, ages 65+ (\%) & 0.003 & 0.001 \\
& $(0.005)$ & $(0.005)$ \\
Confirmed Cases $\times$ Population density (100/km2) & 0.003 & 0.002 \\
& $(0.007)$ & $(0.007)$ \\
Confirmed Cases $\times$ Weekend & -0.017 & -0.017 \\
& $(0.029)$ & $(0.029)$ \\
Confirmed Cases $\times$ Democracy (FH/Polity) & \multicolumn{2}{c}{$0.019^{* * *}$} \\
& $(0.007)$ \\
Confirmed Cases $\times$ Quality of Government $(\mathrm{ICRG})$ & \multicolumn{2}{c}{$-0.032^{* *}$} \\
& $(0.014)$ \\
Constant & $-0.359^{* * *}-0.376^{* * *}$ \\
& $(0.082)$ & $(0.077)$ \\
\hline Observations & 812 & 893 \\
Countries & 113 & 108 \\
Country Fixed Effects & Yes & Yes \\
Cubic Splines & Yes & Yes \\
\hline \hline
\end{tabular}

Robust standard errors in parentheses, clustered at the country level. ${ }^{*} p<0.10$, ${ }^{* *} p<0.05,{ }^{* * *} p<0.01$. 